\title{
RAF1 is increased in labouring myometrium and modulates inflammation-induced pro-labour mediators
}

\author{
Martha Lappas ${ }^{1,2}$ \\ ${ }^{1}$ Mercy Perinatal Research Centre, Mercy Hospital for Women, Heidelberg, Victoria, Australia and ${ }^{2}$ Obstetrics, \\ Nutrition and Endocrinology Group, Department of Obstetrics and Gynaecology, Mercy Hospital for Women, \\ University of Melbourne, Level 4/163 Studley Road, Heidelberg 3084, Victoria, Australia
}

Correspondence should be addressed to M Lappas; Email: mlappas@unimelb.edu.au

\begin{abstract}
Inflammation plays a central role in the terminal process of human labour and delivery, including myometrial contractions. RAF1 protooncogene serine/threonine-protein kinase (RAF1) can activate ERK (official gene symbol MAPK1) and/or nuclear factor-kappa B (NF- $\kappa$ B) to regulate genes involved in inflammation. There are, however, no studies on the role of RAF1 in the processes of human labour and delivery. Thus, the aims of this study were to determine the effect of i) human labour and pro-inflammatory cytokines interleukin 1 beta (IL1B) and tumour necrosis factor (TNF) alpha on RAF1 protein expression in myometrium and ii) siRNA knockdown of RAF1 on proinflammatory and pro-labour mediators in human myometrial primary cells. Term labour was associated with an increase in RAF1 protein expression. Furthermore, RAF1 protein expression was increased in myometrial cells treated with IL1B and TNF, two likely factors contributing to preterm birth. Knockdown of RAF1 by siRNA in primary myometrial cells significantly decreased IL1B- and TNF-induced IL1A, IL1B, IL6, (C-X-C motif) ligand 8 (CXCL8) and chemokine (C-C motif) ligand 2 (CCL2) mRNA abundance and IL6, IL8 and CCL2; prostaglandin-endoperoxide synthase 2 (PTGS2) mRNA levels and prostaglandin PGF $_{2 \alpha}$ release; and NF- $\kappa$ B activation. Furthermore, RAF1 knockdown was associated with decreased activation of ERK in the presence of IL1B but not TNF. Concordantly, the ERK inhibitor U0126 significantly decreased IL1B-induced IL6, CXCL8, CCL2 and PTGS2 mRNA abundance; IL6, CXCL8, CCL2 and PGF $2 \alpha$ release; and NF- $\kappa B$ activation. In conclusion, IL1B induces the expression and secretion of pro-labour mediators through the RAF1-MAPK1-NF- $\kappa B$ signalling pathway. TNF, on the other hand, regulates pro-labour mediators through the RAF1-NF- $\mathrm{B}$ signalling pathway via an
\end{abstract} MAPK1-independent mechanism.

Reproduction (2016) 151 411-420

\section{Introduction}

Preterm birth is the biggest cause of neonatal morbidity and mortality (Blencowe et al. 2013). Currently, there are no effective strategies to prevent preterm birth due to an incomplete understanding of the underlying mechanisms involved in human labour and delivery. What we do know is that inflammation is central to both human term and preterm labour (Christiaens et al. 2008, Shynlova et al. 2013), with an influx of inflammatory cells into the uterus (Thomson et al. 1999, Osman et al. 2003). Cytokines, such as interleukin 1 beta (IL1B) and tumour necrosis factor (TNF) alpha, released by leukocytes, promote the synthesis of prostaglandinendoperoxide synthase 2 (PTGS2)-dependent prostaglandins which are important regulators of myometrial contractility (Bartlett et al. 1999, Erkinheimo et al. 2000, Rauk \& Chiao 2000).

RAF1 proto-oncogene serine/threonine-protein kinase, also known as cRaf or RAF1, is a member of the Raf kinase family of serine/threonine-specific protein kinases that also consists of A-Raf and B-Raf. RAF1 is principle component of the ERK (official gene symbol MAPK1) pathway; it acts as a MAP kinase kinase kinase (MAP3K) initiating the entire kinase cascade. Once activated, RAF1 can phosphorylate to activate the dualspecific MAP kinase/ERK kinase 1 (MEK1) and MEK2, which in turn phosphorylate to activate the serine/threonine-specific protein kinases ERK1 and ERK2 (Alessi et al. 1994). Pleiotropic functions of activated MAPK1 include regulation of genes involved in the cell division cycle, apoptosis, cell differentiation and cell migration (Meloche \& Pouyssegur 2007, Mebratu \& Tesfaigzi 2009, Roskoski 2012). ERK can also activate many transcription regulators, including nuclear factor-kappa B (NF- $\mathrm{KB}$ ) (Nakano et al. 1998, Lu et al. 2010). Notably, many other non-MEK/MAPK1-mediated functions of RAF1 have been postulated (Chen et al. 2001, Ehrenreiter et al. 2005, 2009), including regulation of NF- $\kappa B$ signalling (Baumann et al. 2000, Edelblum et al. 2008a,b).

$\mathrm{NF}-\kappa \mathrm{B}$ is a pro-inflammatory transcription factor that plays a central role in the regulation of the genes 
involved in the terminal effector pathways of human labour and delivery (Lappas et al. 2002, 2003, Lindstrom \& Bennett 2005, Lappas \& Rice 2007). In human myometrium, IL1B and TNF can induce NF- $\kappa B$ activation to induce the expression of pro-inflammatory cytokines and PTGS2 (Khanjani et al. 2012, Liong \& Lappas 2015). Similarly, emerging evidence suggests that MAPK1 also regulates pro-labour mediators in human gestational tissues. In human placenta and foetal membranes, inhibition of MAPK1 using U0126 is associated with decreased lipopolysaccharide (LPS)- or IL1B-induced pro-inflammatory cytokines (Lappas et al. 2007) and matrix degrading enzymes (Lappas et al. 2011), while in human myometrium, MAPK1 is activated during contractions (Paul et al. 2011). In non-gestational tissues, there is ample evidence that RAF1 regulates inflammation. For example, in RAW 264.7 mouse macrophages, inhibition of RAF1 blocks LPS-induced $T N F$ mRNA expression, while overexpression of RAF1 augments LPS-induced TNF mRNA expression (Geppert et al. 1994). Similarly, adenovirus infection stimulates the Raf/MAPK1 signalling pathway and induces chemokine (C-X-C motif) ligand 8 (CXCL8) expression in HeLa cells (Bruder \& Kovesdi 1997). There are, however, no studies on RAF1 in myometrium and its role in regulating inflammation.

Thus, the hypothesis to be tested is that RAF1 expression is increased in myometrium with human labour and mediators of preterm labour, and inhibition of RAF1 is associated with decreased expression of proinflammatory and pro-labour mediators. The aims of this study were to determine i) the effect of human term spontaneous labour and pro-inflammatory cytokines on $R A F 1$ expression in human myometrium, ii) the effect of RAF1 siRNA knockdown on inflammation-induced pro-labour mediators in primary cells isolated from human myometrium and iii) if RAF1 regulates pro-labour mediators via ERK- and/or NF-KB-dependent mechanisms.

\section{Materials and methods}

\section{Tissue collection}

The Research Ethics Committee of Mercy Hospital for Women approved this study. Written, informed consent was obtained from all participating women. All tissues were obtained from women who delivered healthy, singleton infants. All tissues were brought to the research laboratory and processed within 15 min of the caesarean delivery. Women with any underlying medical conditions such as diabetes, asthma, polycystic ovarian syndrome, pre-eclampsia and macrovascular complications were excluded. Additionally, women with multiple pregnancies, obese women, foetuses with chromosomal abnormalities were excluded.

Myometrium was obtained from consenting women at the time of term caesarean section ( $\geq 37$-week gestation). Myometrial biopsies, obtained from the upper margin of the lower uterine segment incision during the caesarean section, were collected from two groups of women: i) pregnant women undergoing elective caesarean section in the absence of labour ( $n=8$ patients; mean gestational age $39.4 \pm 0.3$ weeks) and ii) pregnant women who delivered during active labour; labour was defined as the presence of regular uterine contractions (every 3-4 min), resulting in cervical effacement and dilation ( $n=8$ patients; mean gestational age $39.8 \pm 0.2$ weeks). Indications for caesarean section in the absence of labour were breech presentation and/or previous caesarean section. Indications for caesarean section in the labouring samples were for placenta praevia, foetal distress and delayed or failure to progress. There was no difference in maternal age and BMI, parity or gestational age of the patients recruited. In the labouring group, none of the patients received any medications to augment or induce labour, and the average length of labour was $10 \pm 6 \mathrm{~h} 40 \mathrm{~min}$. Tissue samples were fixed and paraffin embedded for immunohistochemistry (IHC) analysis, or snap frozen in liquid nitrogen and immediately stored at $-80^{\circ} \mathrm{C}$ for analysis by western blot, as detailed below.

\section{Primary myometrial cell culture}

Primary myometrial cells were used to investigate the effect of pro-inflammatory cytokines on RAF1 expression and the effect of RAF1 siRNA (siRAF1) and U0126 (MAPK1 inhibitor) on the expression of pro-labour mediators. Fresh myometrium was obtained from women who delivered healthy, singleton infants at term (37-41 weeks gestation) undergoing elective caesarean section in the absence of labour. Cells were isolated and cultured, as described previously (Lim et al. 2013). Briefly, myometrium was minced and digested for $1 \mathrm{~h}$ in DMEM/ Nutrient Mixture F12 Ham (DMEM/F12) with $3 \mathrm{mg} / \mathrm{ml}$ type 1 collagenase (Worthington Biochemical, Freehold, NJ, USA) and $80 \mu \mathrm{g} / \mathrm{ml}$ DNase 1 (Roche Diagnostics) at $37^{\circ} \mathrm{C}$. Cells were centrifuged at $400 \mathrm{~g}$ for $10 \mathrm{~min}$ and grown in DMEM/F12 enriched with $10 \%$ heat-inactivated FCS (containing $100 \mathrm{U} / \mathrm{ml}$ penicillin $\mathrm{G}$ and $100 \mathrm{mg} / \mathrm{ml}$ streptomycin).

To determine the effect of pro-inflammatory cytokines on RAF1 expression and the ERK inhibitor U0126 on pro-labour mediators, cells at $\sim 80 \%$ confluence were incubated in the absence or presence of $1 \mathrm{ng} / \mathrm{ml}$ IL1B (PeproTech, Rocky Hill, $\mathrm{NJ}$, USA) or $10 \mathrm{ng} / \mathrm{ml}$ TNF (PeproTech) with or without $5 \mu \mathrm{M}$ U0126 (Tocris, Minneapolis, MN, USA) for $20 \mathrm{~h}$. The concentrations of IL1B and TNF are based on previous studies in myometrial cells (Liong \& Lappas 2015). Cells were collected and stored at $-80{ }^{\circ} \mathrm{C}$ until assayed for mRNA expression by qRT-PCR. Media was collected and stored at $-80{ }^{\circ} \mathrm{C}$ until assayed for cytokine and prostaglandin release, as detailed below. Experiments were performed from myometrium obtained from five patients.

For the siRAF1 studies, transfection of primary myometrial cells was performed, as we have previously described (Lappas 2015). Briefly, cells at $\sim 50 \%$ confluence were transfected using Lipofectamine 3000, according to manufacturer's guidelines (Life Technologies). siRAF1 and negative control siRNA (siCONT) was obtained from OriGene (Rockville, MD, USA). Cells were transfected with $200 \mathrm{nM}$ siRAF1 or $200 \mathrm{nM}$ siCONT in DMEM/F12 for $48 \mathrm{~h}$. The medium was then 
replaced with DMEM/F12 (containing $0.5 \%$ BSA) with or without $1 \mathrm{ng} / \mathrm{ml} \mathrm{IL1B}$ or $10 \mathrm{ng} / \mathrm{ml} \mathrm{TNF}$, and the cells were incubated at $37^{\circ} \mathrm{C}$ for an additional $20 \mathrm{~h}$. Cells were collected and stored at $-80{ }^{\circ} \mathrm{C}$ until assayed for mRNA expression by qRT-PCR and protein expression by western blotting, as detailed below. Media was collected and stored at $-80^{\circ} \mathrm{C}$ until assayed for cytokine and prostaglandin release, as detailed below. Cell viability was assessed by the 3-(4,5-dimethyl-2-thiazolyl)-2,5-diphenyl-2H-tetrazolium bromide (MTT) proliferation assay, as we have previously described (Lim et al. 2014). The response to IL1B and TNF between patients varied greatly, as we have previously reported (Lappas 2015). Thus, data are presented as fold change in expression relative to the expression level in the IL1B- or TNF-stimulated siCONT-transfected cells, which was set at one. Data could not be normalised to siCONT-transfected cells alone, as some of the readings were zero. Experiments were performed from myometrium obtained from five patients.

\section{NF-KB luciferase assay}

A luciferase assay was utilised to determine possible interactions between RAF1 and NF- $\kappa \mathrm{B}$, as described previously (Lim et al. 2016). Primary myometrial cells, prepared as described above, at $\sim 70 \%$ confluence, were transfected with 0.75 ng NF- $\kappa$ B reporter construct (Qiagen, Chadstone Centre) using FuGENE HD transfection reagent (Promega). After $6 \mathrm{~h}$, cells were transfected with $200 \mathrm{nM}$ of siRAF1 or siCONT (as detailed above) for $48 \mathrm{~h}$. The medium was then replaced with DMEM/F12 (containing $0.5 \% \mathrm{BSA}$ ), with or without $1 \mathrm{ng} / \mathrm{ml} \mathrm{IL1B}$ or $10 \mathrm{ng} / \mathrm{ml} \mathrm{TNF}$, and the cells incubated at $37^{\circ} \mathrm{C}$ for an additional $20 \mathrm{~h}$.

To determine the effect of U0126 on NF- $\kappa \mathrm{B}$ activity, primary myometrial cells were transfected with $0.75 \mathrm{ng} N \mathrm{~N}-\kappa \mathrm{B}$ reporter construct, as detailed above. After $48 \mathrm{~h}$ incubation, cells were treated with $1 \mathrm{ng} / \mathrm{ml} \mathrm{IL1B}$ in the absence or presence of $5 \mu \mathrm{M}$ U0126 and the cells incubated at $37{ }^{\circ} \mathrm{C}$ for an additional $20 \mathrm{~h}$.

After final incubation, cells were harvested in lysis buffer, and luminescence activity was measured using a Luciferase Reporter Assay kit (Life Research, Scoresby, Australia) and Renilla Luciferase Flash Assay kit (Thermo Fisher Scientific; Scoresby, Australia) as instructed. The ratio of the firefly luciferase level to the Renilla luciferase level was determined, and the results are expressed as a ratio of normalised luciferase activity. The experiments were performed from myometrium obtained from five patients.

\section{Immunohistochemistry}

To determine the expression of RAF1 in myometrium, IHC was performed on paraffin sections, as described previously (Lappas 2015) using the IHC Select HRP Detection Set (Merck Millipore). Briefly, sections were deparaffinised followed by an antigen retrieval step (boiled in $10 \mathrm{mM}$ Tris, $1 \mathrm{mM}$ EDTA, $\mathrm{pH} 9.0$ for $10 \mathrm{~min}$, followed by $20 \mathrm{~min}$ incubation) and then endogenous peroxidases were inactivated by adding $3 \%$ hydrogen peroxide for $10 \mathrm{~min}$. After blocking (Blocking Reagent: normal goat serum in PBS) for $5 \mathrm{~min}$, sections were incubated with $1 \mu \mathrm{g} / \mathrm{ml}$ rabbit polyclonal anti-RAF1
(GTX107763; GeneTex, CA, USA) in 1\% (wt/vol) BSA in PBS and incubated in a humidity chamber at $4{ }^{\circ} \mathrm{C}$ overnight. Binding sites were labelled with biotin-conjugated rabbit antigoat IgG antibody followed by the streptavidin-HRP. Negative control slides, where primary antibody was replaced with rabbit IgG, were also performed.

\section{RNA extraction and $q R T-P C R$}

RNA extraction and qRT-PCR was performed, as described previously (Lim et al. 2016). Briefly, total RNA was extracted from cells using TRIsure reagent, according to manufacturer's instructions (Bioline; Alexandria, Australia). RNA concentration and purity were measured using a NanoDrop ND-1000 spectrophotometer (Thermo Fisher Scientific; Scoresby, Australia). RNA $(0.2 \mu \mathrm{g})$ was converted to cDNA using the Tetro cDNA Synthesis kit (Bioline), according to the manufacturer's instructions. The RT-PCR was performed using the CFX384 real-time PCR detection system (Bio-Rad Laboratories) using $100 \mathrm{nM}$ of pre-designed and validated QuantiTect primers (Qiagen). Average gene $\mathrm{Ct}$ values were normalised against two housekeeping genes (beta-2-microglobulin (B2M) and succinate dehydrogenase complex flavoprotein subunit A $(S D H A))$. Of note, there was no effect of experimental treatment on $B 2 M$ or SDHA mRNA expression. Fold differences were determined using the comparative Ct method.

\section{Western blotting}

Western blotting was performed, as described previously (Lim et al. 2016). Blots were incubated in $1 \mu \mathrm{g} / \mathrm{ml}$ rabbit polyclonal anti-RAF1 (GTX107763; GeneTex, CA, USA), $1 \mu \mathrm{g} / \mathrm{ml}$ rabbit polyclonal anti-MAPK1 (sc-93; Santa Cruz Biotechnology) or $1 \mu \mathrm{g} / \mathrm{ml}$ mouse monoclonal anti-phosphorylated MAPK1 (sc-7383; Santa Cruz Biotechnology) prepared in blocking buffer (5\% skim milk in TBS with $0.05 \%$ Tween-20) for $16 \mathrm{~h}$ at $4{ }^{\circ} \mathrm{C}$. Membranes were viewed and analysed using the ChemiDoc XRS system (Bio-Rad Laboratories). Semi-quantitative analysis of the relative density of the bands in western blots was performed using Quantity One 4.2.1 Image Analysis Software (Bio-Rad Laboratories). For the labour studies, RAF1 protein expression was normalised to Ponceau $S$ stain, as described previously (Lim et al. 2016); a section of the Ponceau S stained membrane was chosen which did not show variation with labour status.

\section{Cytokine and prostaglandin assays}

The release of IL6, CXCL8 and chemokine (C-C motif) ligand 2 (CCL2) was performed using CytoSet sandwich ELISA, according to the manufacturer's instructions (Life Technologies). The limit of detection of the IL6, CXCL8 and CCL2 assays was 16,12 and $15 \mathrm{pg} / \mathrm{ml}$ respectively. The release of $\mathrm{PGF}_{2 \alpha}$ into the incubation medium was assayed using a commercially available competitive enzyme immunoassay kit, according to the manufacturer's specifications (Kookaburra Kits from Sapphire Bioscience, Redfern, NSW, Australia). The limit of detection of the $\mathrm{PGF}_{2 \alpha}$ assay was $60 \mathrm{pg} / \mathrm{ml}$. For all assays, the inter- and intra-assay coefficients of variation were $<10 \%$. 

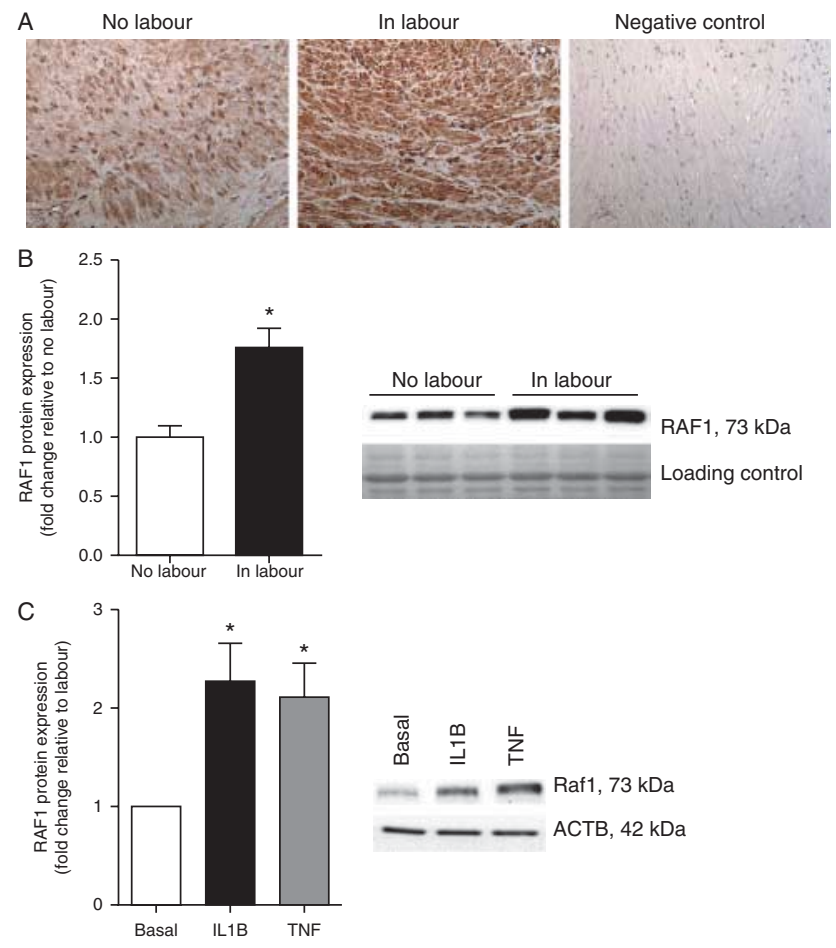

Figure 1 Effect of human labour and pro-inflammatory cytokines on RAF1 expression in myometrium. (A and B) Human myometrium was obtained from non-labouring and labouring women at term caesarean section ( $n=8$ patients/group). (A) immunohistochemical expression of RAF1. These sections are representative of one patient sample per group. Negative control is also displayed; original magnification $\times 100$. (B) RAF1 protein expression was analysed by western blotting and Ponceau $S$ stain was used as a loading control. The fold change was calculated relative to no labour group. All data are displayed as mean \pm S.E.M. ${ }^{*} P<0.05$ vs no labour (Student's $t$-test). Representative western blot from three patients per group is also shown. (C) Human primary myometrial cells were incubated in the absence or presence of $1 \mathrm{ng} / \mathrm{ml}$ IL $1 \mathrm{~B}$ or $10 \mathrm{ng} / \mathrm{ml} \mathrm{TNF}$ for $20 \mathrm{~h}$ ( $n=4$ patients). RAF1 protein expression was analysed by western blot. Protein expression was normalised to ACTB, and the fold change was calculated relative to basal. All data are displayed as mean \pm s.E.M. ${ }^{*} P<0.05$ vs basal (one sample $t$-test). Representative western blot from one patient is also shown.

\section{Statistical analysis}

Statistics was performed on the normalised data unless otherwise specified. All statistical analyses were undertaken using GraphPad Prism (GraphPad Software, La Jolla, CA, USA). For Fig. 1B, an unpaired Student's $t$-test was used to assess statistical significance between normally distributed data; otherwise, the non-parametric Mann-Whitney $U$ was used. For Fig. 1C, one sample $t$-test, against the constant of one, was used. For Figs 2, 3, 4, 5 and 6, the homogeneity of data was assessed by Bartlett's test, and when significant, the data were logarithmically transformed before further analysis. The data were analysed by one-way ANOVA using Fisher's least significant difference post hoc test to allow multiple comparisons between groups. Statistical significance was ascribed to $P$ value $<0.05$. Data were expressed as mean \pm s.E.M., unless otherwise specified.

\section{Results}

\section{Effect term labour on RAF1 expression in human myometrium}

To determine the effect of spontaneous term labour on RAF1 expression, myometrium was obtained from women at term caesarean section in the absence of labour (term no labour; $n=8$ patients) and after spontaneous labour onset (term in labour; $n=8$ patients). IHC revealed that RAF1 staining was present in the longitudinal and transverse muscle fibres (Fig. 1A); staining of RAF1 was more intense in the labouring group. No non-specific staining was present in the negative control. RAF1 protein expression, as analysed by western blotting, was also significantly higher in
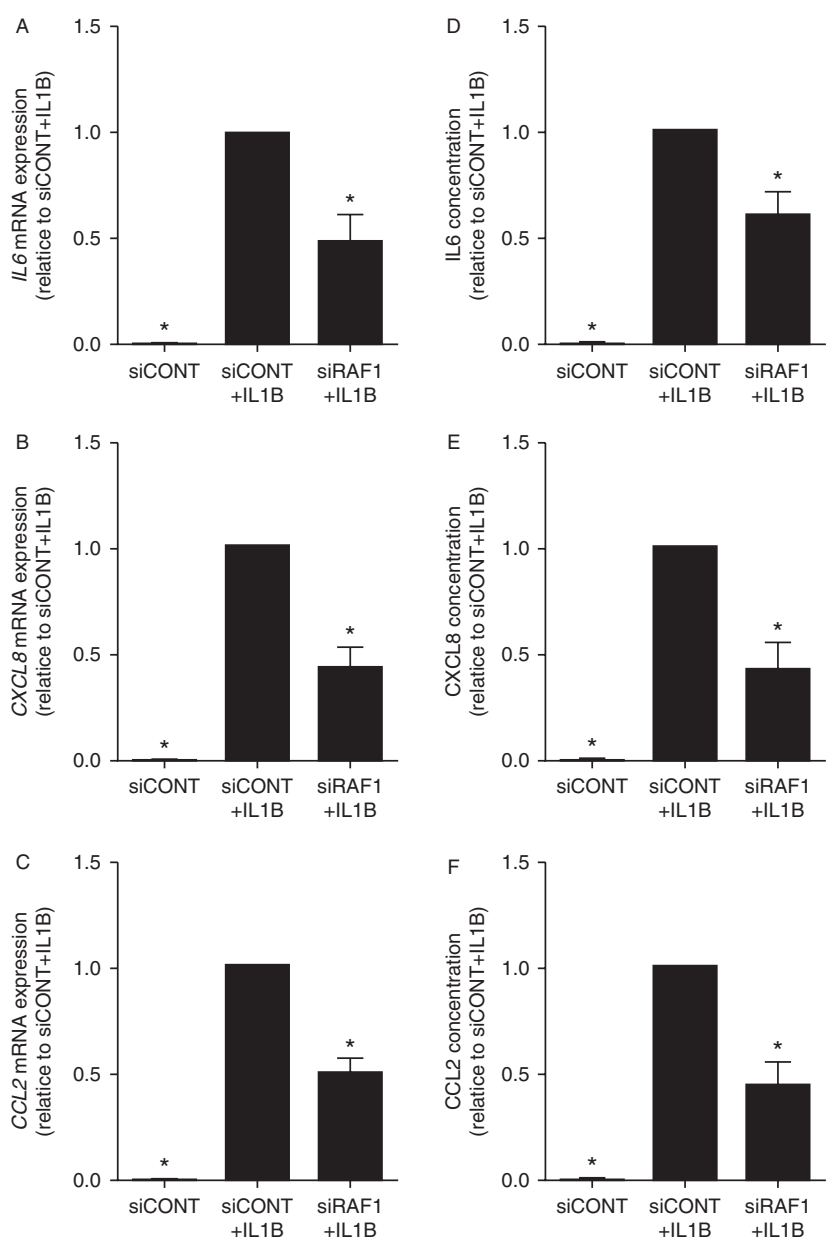

Figure 2 Effect of siRAF1 knockdown on IL1B-induced pro-inflammatory cytokines and chemokines. Human primary myometrial cells were transfected with or without $200 \mathrm{nM}$ siRAF1 or siCONT for $48 \mathrm{~h}$ and then treated with $1 \mathrm{ng} / \mathrm{ml}$ IL1B for an additional $20 \mathrm{~h}(n=5$ patients). (A, B and C) IL6, CXCL8 and CCL2 mRNA abundance was analysed by qRT-PCR, and the fold change was calculated relative to IL1B-stimulated siCONT-transfected cells. (D, E and F) IL6, CXCL8 and CCL2 concentration in the incubation medium was assayed by ELISA. The fold change was calculated relative to IL1B-stimulated siCONTtransfected cells. All data are displayed as mean \pm S.E.M. ${ }^{*} P<0.05$ vs IL1B-stimulated siCONT-transfected cells (one-way ANOVA). 

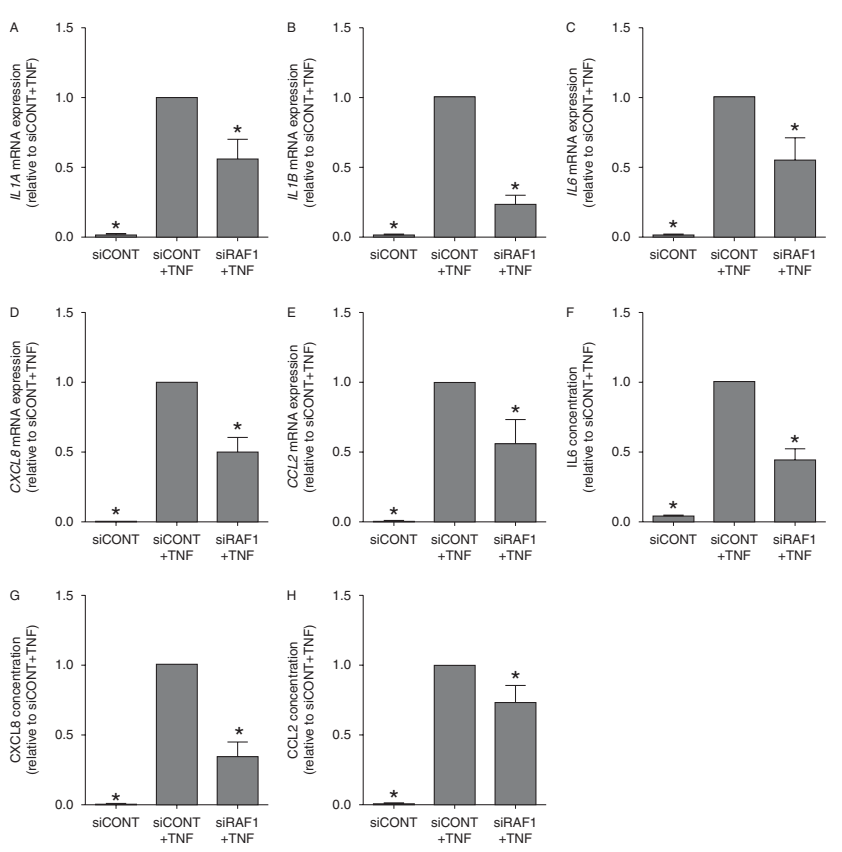

Figure 3 Effect of siRAF1 knockdown on TNF-induced pro-inflammatory cytokines and chemokines. Human primary myometrial cells were transfected with or without $200 \mathrm{nM}$ siRAF1 or siCONT for $48 \mathrm{~h}$ and then treated with $10 \mathrm{ng} / \mathrm{ml} \mathrm{TNF}$ for an additional $20 \mathrm{~h}(n=5$ patients). (A, B, C, D and E) IL1A,IL1B, IL6, CXCL8 and CCL2 mRNA abundance was analysed by GRT-PCR and the fold change was calculated relative to TNF-stimulated siCONT-transfected cells. $(\mathrm{F}, \mathrm{G}$ and $\mathrm{H}) \mathrm{IL6}, \mathrm{CXCL8}$ and CCL2 concentration in the incubation medium was assayed by ELISA. The fold change was calculated relative to TNF-stimulated siCONT-transfected cells. All data are displayed as mean \pm S.E.M. ${ }^{*} P<0.05$ vs TNF-stimulated siCONT-transfected cells (one-way ANOVA).

labouring myometrium when compared to non-labouring samples (Fig. 1B).

\section{Effect of pro-inflammatory cytokines on RAF1 expression in human myometrium}

The pro-inflammatory cytokines IL1B and TNF have been shown to induce preterm birth in vivo (Sadowsky et al. 2006). Thus, the next aim was to determine the effect of IL1B or TNF on the expression of RAF1 in primary human myometrial cells. As shown in Fig. 1C, incubation of myometrial cells with IL1B or TNF significantly increased RAF1 protein expression.

\section{Effect of siRAF1 on pro-inflammatory cytokines and chemokines in primary myometrium cells}

Given that pro-inflammatory cytokines increase RAF1 expression in human myometrium, we next sought to determine if RAF1 regulates the formation of proinflammatory and pro-labour mediators induced by IL1B and TNF. For these studies, primary myometrial cells isolated from fresh myometrial tissue were used, and knockdown of RAF1 was performed by siRNA. The efficacy of transfection was analysed by qRT-PCR and western blotting (Supplementary Figure S1, see section on supplementary data given at the end of this article). When compared to siCONT-transfected cells, siRAF1 transfection resulted in $80 \%$ decrease in RAF1 mRNA expression and $60 \%$ decrease in RAF1 protein expression. There was no effect of siRAF1 on cell viability as determined by MTT assay.

The next aim was to determine the importance of RAF1 in the expression of inflammation-induced pro-labour mediators. Thus, for all subsequent experiments, after
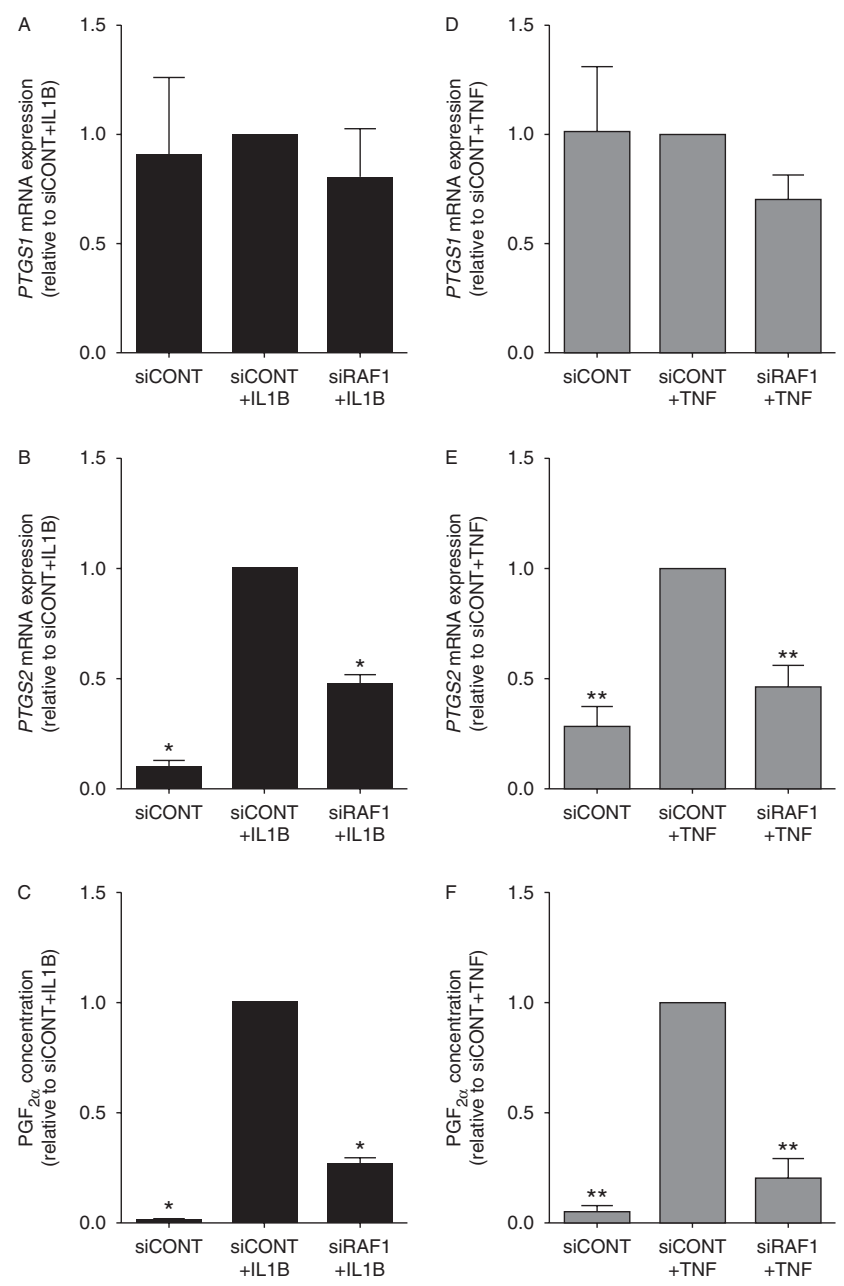

Figure 4 Effect of siRAF1 knockdown on the PTGS2-prostaglandin pathway. Human primary myometrial cells were transfected with or without $200 \mathrm{nM}$ siRAF1 or siCONT for $48 \mathrm{~h}$ and then treated with (A, B and C) $1 \mathrm{ng} / \mathrm{ml}$ IL $1 \mathrm{~B}$ or (D, E and F) $10 \mathrm{ng} / \mathrm{ml}$ TNF for an additional $20 \mathrm{~h}$ ( $n=5$ patients). (A, B, D and E) PTGS1 and PTGS2 mRNA abundance was analysed by qRT-PCR and the fold change was calculated relative to IL1B- or TNF-stimulated siCONT-transfected cells. (C and F) PGF PA $_{2 \alpha}$ concentration in the incubation medium was assayed by ELISA, and the fold change was calculated relative to IL1B- or TNF-stimulated siCONT-transfected cells. All data are displayed as mean \pm S.E.M. $* P<0.05$ vs IL1B-stimulated siCONT-transfected cells (one-way ANOVA); ${ }^{* *} P<0.05$ vs TNF-stimulated siCONT-transfected cells (one-way ANOVA). 

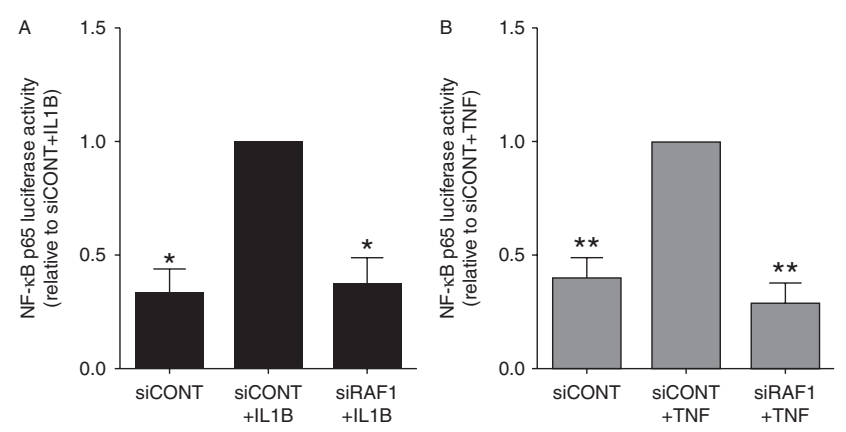

Figure 5 Effect of siRAF1 knockdown on NF-kB activation. Human myometrial cells were transfected with $0.75 \mathrm{ng} N \mathrm{~N}-\kappa \mathrm{B}$ reporter construct. After $6 \mathrm{~h}$, cells were transfected with $200 \mathrm{nM}$ siRAF1 or siCONT for $48 \mathrm{~h}$, then treated with (A) $1 \mathrm{ng} / \mathrm{ml} \mathrm{IL1B}$ or (B) $10 \mathrm{ng} / \mathrm{ml}$ TNF for an additional $20 \mathrm{~h}$ ( $n=5$ patients). Promoter activity (normalised with Renilla expression) is expressed as a ratio of luciferase activity of IL1B- or TNF-stimulated siCONT-transfected cells. All data are displayed as mean \pm s.E.M. ${ }^{*} P<0.05$ vs IL1B-stimulated siCONTtransfected cells (one-way ANOVA); ${ }^{* *} P<0.05$ vs TNF-stimulated siCONT-transfected cells (one-way ANOVA).

siRNA transfection, cells were treated with the proinflammatory cytokines IL1B or TNF. Figure 2 demonstrates the effect of siRAF1 on IL1B-induced mRNA levels and secretion of pro-inflammatory cytokines and chemokines. As expected, when compared to siRAF1-transfected cells, IL1B significantly increased IL6, CXCL8 and CCL2 mRNA abundance (Fig. 2A, B and C) and IL6, CXCL8 and CCL2 release (Fig. 2D, E and F). The effect of siRAF1 was a significant suppression of IL1B-induced pro-inflammatory cytokine mRNA abundance and secretion.

The effect of siRAF1 on the expression and release of pro-inflammatory cytokines in the presence of TNF is shown in Fig. 3. In siCONT-transfected cells, IL1A, IL1B, IL6, CXCL8 and CCL2 mRNA abundance (Fig. 3A, B, C, D and $\mathrm{E}$ ) and IL6, CXCL8 and CCL2 release (Fig. 3F, G and H) was significantly augmented by TNF. The effect of siRAF1 transfection was a significant decrease in TNF-induced gene expression and secretion. Of note, the release of IL1A and IL1B were below the sensitivity of the assays.

\section{Effect of siRAF1 on the PTGS2-prostaglandin pathway in primary myometrium cells}

The effect of siRAF1 on the PTGS2-prostaglandin pathway in the presence of IL1B or TNF was also assessed, and the data are presented in Fig. 4. As expected, in siCONT-transfected myometrial cells, treatment with IL1B (Fig. 4B) or TNF (Fig. 4E) induced a significant increase in PTGS2 mRNA expression. Likewise, the release of $\mathrm{PGF}_{2 \alpha}$ was significantly augmented by IL1B (Fig. 4C) or TNF (Fig. 4F) in cells transfected with siCONT. The effect of siRAF1 was a significant decrease in IL1B- or TNF-induced PTGS2 gene expression and $\mathrm{PGF}_{2 \alpha}$ release. Of note, there was no effect of IL1B, TNF or siRAF1 on PTGS1 mRNA expression (Fig. 4A and D).

\section{Silencing of RAF1 represses NF- $B$ B 655 transcriptional activity}

In non-gestational tissues, RAF1 has been shown to regulate inflammation via the pro-inflammatory transcription factor NF-кB (Nakano et al. 1998, Baumann et al. 2000, Roh et al. 2000, Keelan et al. 2003, Lappas \& Rice 2004, Edelblum et al. 2008a,b, Lu et al. 2010). Thus, to determine whether NF- $\kappa B$ is involved in the RAF1 pathway, the effect of siRAF1 on NF- $\kappa B$ transcriptional activity was determined. As expected, treatment with IL1B (Fig. 5A) and TNF (Fig. 5B) significantly increased NF- $\mathrm{KB}$ p65 luciferase activity in siCONTtransfected myometrial cells. The effect of transfection with siRAF1 was a significant decrease in IL1B- and TNF-induced luciferase activity.

\section{Silencing of RAF1 inhibits ERK activation in the presence of IL1B but not TNF}

RAF1 activation initiates an MAPK cascade that leads to the phosphorylation and activation of MAPK1. Thus, we next explored the effect of siRAF1 on activation of MAPK1 by assessing phosphorylation of MAPK1 by western blotting. As shown in Fig. 6A, IL1B-induced

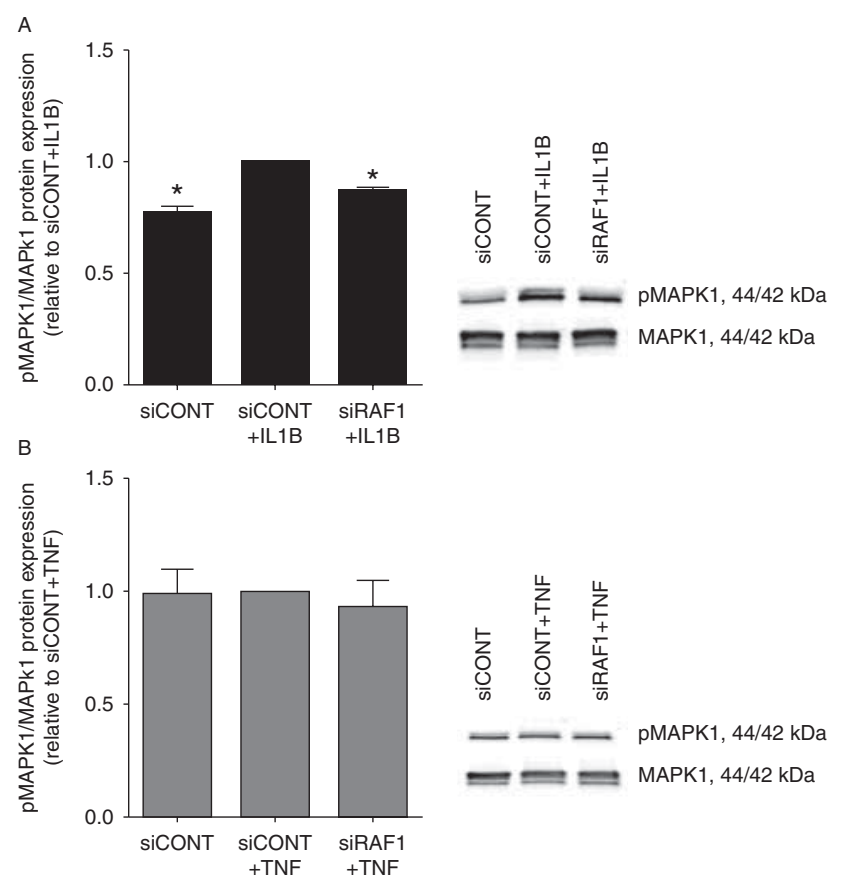

Figure 6 Effect of siRAF1 knockdown on MAPK1 activation. Human primary myometrial cells were transfected with or without $200 \mathrm{nM}$ siRAF1 or siCONT for $48 \mathrm{~h}$ and then treated with (A) $1 \mathrm{ng} / \mathrm{ml} \mathrm{IL1B} \mathrm{or} \mathrm{(B)}$ $10 \mathrm{ng} / \mathrm{ml}$ TNF for an additional $2 \mathrm{~h}$ ( $n=5$ patients). Activated MAPK1 (p-MAPK1) protein expression was assessed by Western blotting, normalised to total MAPK1 protein expression and the fold change was calculated relative to IL1B-stimulated siCONT-transfected cells. Data displayed as mean \pm s.E.M. ${ }^{*} P<0.05$ vs IL1B-stimulated siCONTtransfected cells (one-way ANOVA). Representative Western blot from one patient is also shown. 

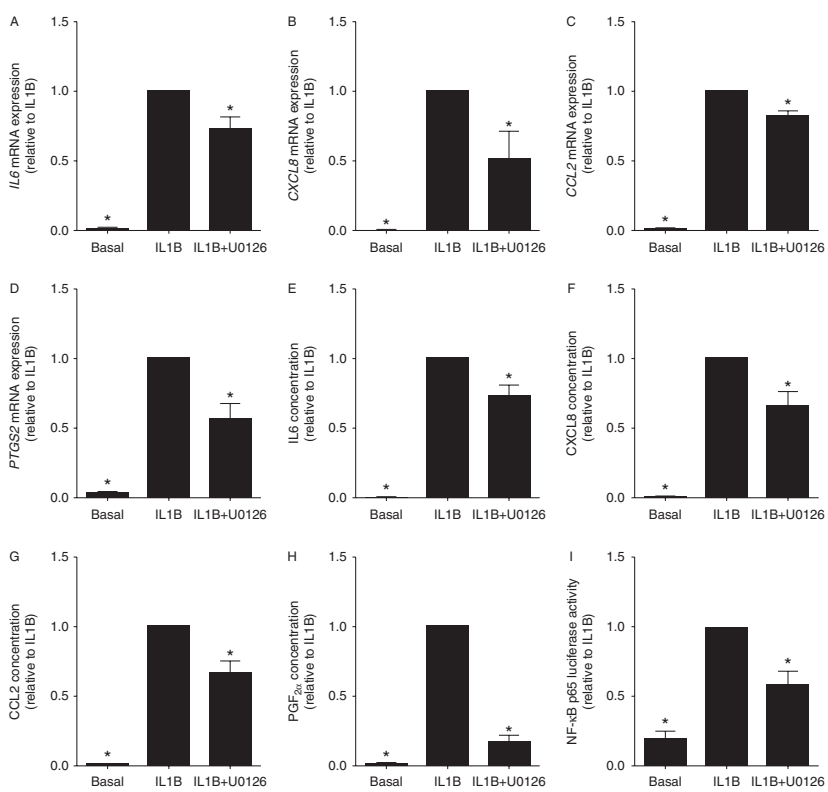

Figure 7 Effect of MAPK1 inhibitor U0126 on IL1B pro-labour mediators. Human primary myometrial cells were incubated in the absence or presence of $5 \mu \mathrm{M} \cup 0126$ with or without $1 \mathrm{ng} / \mathrm{ml}$ IL1B for $20 \mathrm{~h}$ ( $n=5$ patients). (A, B, C and D) IL6, CXCL8, CCL2 and PTGS2 mRNA abundance was analysed by qRT-PCR and the fold change was calculated relative to IL1B. (E, F and H) IL6, CXCL8, CCL2 and $\mathrm{PGF}_{2 \alpha}$ Concentration in the incubation medium was assayed by ELISA. The fold change was calculated relative to IL1B. (I) Human myometrial cells were transfected with $0.75 \mathrm{ng} N \mathrm{~F}-\kappa \mathrm{B}$ reporter construct. After $48 \mathrm{~h}$, cells were treated with $1 \mathrm{ng} / \mathrm{ml}$ IL1B for an additional $20 \mathrm{~h}$ ( $n=5$ patients). Promoter activity (normalised with Renilla expression) is expressed as a ratio of luciferase activity of IL1B. All data are displayed as mean \pm s.E.M. ${ }^{*} P<0.05$ vs IL1B (one-way ANOVA).

phosphorylation of MAPK1 was significantly attenuated in cells transfected with siRAF1. There was, however, no effect of TNF with or without siRAF1 on MAPK1 activation (Fig. 6B). These findings suggest that RAF1 may regulate IL1B-induce pro-labour mediators via activation of MAPK1 while RAF1 regulates TNF-induced pro-labour mediators via MAPK 1 -independent mechanisms. Thus, to confirm a role for MAPK1 in the regulation of IL1Bstimulated pro-labour mediators, primary myometrial cells were incubated in the presence of IL1B with or without the specific MAPK1 inhibitor U0126. As shown in Fig. 7, treatment of myometrial cells with $U 0126$ significantly decreased IL1B-induced IL6, CXCL8, CCL2 and PTGS2 mRNA abundance (Fig. 7A, B, C and D) and IL1B-induced IL6, CXCL8, CCL2 and $\mathrm{PGF}_{2 \alpha}$ secretion

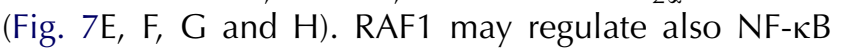
activation via MAPK1-dependent or -independent actions. Thus, to determine if IL1B-induced NF- $\kappa B$ is dependent on MAPK1 activation, the effect of the MAPK1 inhibitor U0126 on NF- $\kappa B$ transcriptional activity was determined. As shown in Fig. 7l, the increase in NF- $\kappa B$ p65 luciferase activity induced by IL1B was significantly attenuated by treatment with $\cup 0126$.

\section{Discussion}

In this study, it is reported, for the first time, that RAF1 is increased in labouring myometrium and in response to the pro-inflammatory cytokines IL1B and TNF. Further, a novel role for RAF1 in the genesis of pro-labour mediators, induced by inflammation, is also demonstrated. Specifically, IL1B induces the expression and secretion of pro-inflammatory cytokines and chemokines, PTGS2 expression and prostaglandin secretion in primary myometrial cells through the RAF1-MAPK1NF- $\kappa B$ signalling pathway. TNF, on the other hand, induces the expression and secretion of pro-inflammatory cytokines and chemokines, PTGS2 expression and prostaglandin release through the RAF1-NF- $\mathrm{B} B$ signalling pathway via an MAPK1-independent mechanism. Aberrant RAF1 expression may thus establish an autocrine loop, which results in the continuous stimulation of inflammation.

Human term labour is a sterile inflammatory process (Christiaens et al. 2008). Activation of maternal immune system leads to a massive influx of leukocytes in the uterus and myometrium through the release of chemokines such as CXCL8 and CCL2 (Thomson et al. 1999). Infiltrating leukocytes augments the pro-inflammatory microenvironment through the release pro-inflammatory cytokines to amplify or initiate the process of parturition. Thus, increased RAF1 expression in human term labouring myometrium suggests that it may be a consequence of this increased inflammation. In support, treatment of human primary myometrial cells with the pro-inflammatory cytokines IL1B or TNF significantly increased RAF1 expression.

IL1B, which is released from infiltrating leukocytes in the uterus and myometrium, is a key pro-inflammatory cytokine involved in human parturition. Human labour is associated with increased concentrations of IL1B in both gestational tissues and biological fluids (Elliott, et al. 2001, Bowen et al. 2002, Tattersall et al. 2008), and intra-amniotic and/or systemic administration of IL1B to mice and monkeys induces preterm labour (Romero et al. 1991, Romero \& Tartakovsky 1992, Sadowsky et al. 2006). IL1B is thought to contribute to the onset of labour by stimulating and potentiating uterine contractions. It induces basal and store-operated calcium entry in myometrial smooth muscle cells (Tribe et al. 2003), thus directly enhancing their contractile potential. IL1B can also increase the production of pro-inflammatory cytokines and chemokines; promote the production of prostaglandins via PTGS2, mediators of uterine contractions; and matrix metalloproteinases (MMPs) which activate cervical ripening and foetal membrane rupture, events culminating in successful labour and delivery (Roh et al. 2000, Bowen et al. 2002, Keelan et al. 2003, Lappas \& Rice 2004, Christiaens et al. 2008, Tattersall, et al. 2008). The findings of this study demonstrate that RAF1 is involved in the genesis of pro-inflammatory and 
pro-labour mediators induced by IL1B. Specifically, siRAF1 knockdown in primary myometrial cells was associated with a significant decrease in IL1B-induced expression and secretion of the pro-inflammatory cytokine IL6, the chemokines CXCL8 and CCL2, PTGS2 mRNA expression and subsequent prostaglandin $\mathrm{PGF}_{2 \alpha}$ release.

TNF is another pro-inflammatory cytokine that plays a central role in the terminal effector pathways of human labour and deliver. TNF can amplify or initiate the process of parturition by further increasing cytokine production, increasing PTGS2-mediated prostaglandin synthesis and activating MMPs (Roh et al. 2000, Bowen et al. 2002, Keelan et al. 2003, Lappas \& Rice 2004, Christiaens et al. 2008, Tattersall et al. 2008). In addition, TNF can induce preterm labour in animal models (Sadowsky et al. 2006). Thus, it was also of interest to determine if RAF1 also regulates pro-inflammatory and pro-labour mediators in the presence of TNF. Human primary myometrial cells transfected with siRAF1 released significantly less IL6, CXCL8 and CCL2 when stimulated with TNF. siRAF1-transfected cells also displayed decreased TNF-induced PTGS2 mRNA expression and prostaglandin $\mathrm{PGF}_{2 \alpha}$ release. Collectively, this data indicate that RAF1 is important to TNF signalling pathways associated with preterm birth.

Activation of RAF1 initiates a cascade of events that eventually leads to the activation of MAPK1 (Alessi et al. 1994). Activated MAPK1 has been shown to regulate a number of cellular functions, including inflammation (Kyriakis \& Avruch 1996). Likewise, we have previously shown that MAPK1 regulates LPS-stimulated release of pro-inflammatory cytokines and prostaglandins from human placenta and foetal membranes (Lappas et al. 2007). Furthermore, MAPK1 is involved in IL1B-induced matrix metallopeptidase 9 (MMP9) mRNA expression and pro-MMP9 in human primary amnion cells (Lappas et al. 2011). In this study, knockdown of RAF1 was associated with decreased activation of MAPK1 in the presence of IL1B but not TNF. These findings suggest that, in human myometrium, TNF activates RAF1 to induce the expression of pro-inflammatory and prolabour labour mediators independently of MAPK1. On the other hand, MAPK1 is required for RAF1-mediated inflammation in the presence of IL1B. Thus, the MAPK1 inhibitor U0126 was used to determine if MAPK1 regulates IL1B-induced expression of pro-inflammatory and pro-labour mediators in human myometrium. Indeed, incubation of primary myometrial cells with U0126 significantly decreased IL1B-induced mRNA expression and secretion of the pro-inflammatory cytokine IL6 and the chemokines CXCL8 and CCL2. In addition, IL1B-induced PTGS2 mRNA expression and $\mathrm{PGF}_{2 \alpha}$ secretion was also significantly suppressed by U0126. Collectively, these findings suggest that RAF1 signals through MAPK1 to regulate IL1B-induced pro-inflammatory and pro-labour mediators in human myometrium.

Another candidate for a RAF1 effector is NF- $\kappa$ B, a transcription factor central to the regulation of the terminal effector pathways of human labour and delivery (Lappas et al. 2002, 2003, Lindstrom \& Bennett 2005, Lappas \& Rice 2007). NF-кB is sequestered in the cytosol by its inhibitor protein (nuclear factor of kappa light polypeptide gene enhancer in B-cells inhibitor, alpha; NFKBIA), which upon activation is phosphorylated and targeted for degradation (Karin \& Delhase 2000). In this study, knockdown of RAF1 in primary myometrial cells was associated with decreased IL1B- and TNF-induced $\mathrm{NF}-\kappa \mathrm{B}$ activation. These findings suggest that IL1B and TNF may regulate pro-labour mediators via RAF1 activation of NF- $\kappa \mathrm{B}$. These studies provide a novel functional linkage between pro-inflammatory cytokines and NF- $\kappa B$ signalling, two key players involved in inflammation-driven preterm birth.

Both MAPK1-dependent and -independent mechanisms may be involved in RAF1 activation of NF- $\kappa B$. The MAPK1 substrate p90-RSK can phosphorylate NFKBIA and induce its degradation (Ghoda et al. 1997). In addition, MAPK1 can down-regulate the expression of PAR4, an inhibitor of NF- $\mathrm{BB}$ activation (Barradas et al. 1999). An emerging theme is that RAF1 induces NFKBIA degradation via MEKK1 (MEK kinase 1) independently of MAPK1 (Baumann et al. 2000). For example, RAF1 promotes colon epithelial cell survival through NF- $\kappa B$ downstream of TNF receptor 1 (TNFR1) activation independently of MAPK1 (Edelblum et al. 2008a). In this study, IL1B-induced NF- $\kappa B$ activation is dependent on MAPK1. That is, the MAPK1 inhibitor U0126 significantly attenuated IL1B-induced NF-KB transcriptional activity. Taken together, these findings suggest that IL1B-induced RAF1 activation of NF-KB is dependent on MAPK1.

Collectively, the findings of this study suggest that in human myometrium, IL1B induces the expression of pro-inflammatory and pro-labour mediators via a RAF1MAPK1-NF-кB-dependent pathway. On the other hand, TNF induces the expression of pro-labour mediators via RAF1-NF- $\kappa B$, which was independent of MAPK1. Regulation of RAF1 may constitute a useful therapeutic target for inflammation-induced preterm birth.

\section{Supplementary data}

This is linked to the online version of the paper at http://dx.doi. org/10.1530/REP-15-0607.

\section{Declaration of interest}

The authors declare that there is no conflict of interest that could be perceived as prejudicing the impartiality of the research reported. 


\section{Funding}

Associate Professor Martha Lappas was supported by a Career Development Fellowship from the National Health and Medical Research Council (NHMRC; grant no. 1047025). Additional funding was provided by the Normal Beischer Medical Research Foundation and the Mercy Research Foundation.

\section{Acknowledgements}

The following are gratefully acknowledged: Ratana Lim and Gillian Barker (Obstetrics, Nutrition and Endocrinology Group, Department of Obstetrics and Gynaecology, University of Melbourne) for their excellent technical assistance; the Clinical Research Midwives Genevieve Christophers, Gabrielle Pell and Rachel Murdoch for sample collection; and the Obstetrics and Midwifery staff of the Mercy Hospital for Women for their co-operation.

\section{References}

Alessi DR, Saito Y, Campbell DG, Cohen P, Sithanandam G, Rapp U, Ashworth A, Marshall CJ \& Cowley S 1994 Identification of the sites in MAP kinase kinase-1 phosphorylated by p74raf-1. EMBO Journal 13 1610-1619.

Barradas M, Monjas A, Diaz-Meco MT, Serrano M \& Moscat J 1999 The downregulation of the pro-apoptotic protein Par-4 is critical for Rasinduced survival and tumor progression. EMBO Journal 18 6362-6369. (doi:10.1093/emboj/18.22.6362)

Bartlett SR, Sawdy R \& Mann GE 1999 Induction of cyclooxygenase-2 expression in human myometrial smooth muscle cells by interleukin-1 $\beta$ : involvement of p38 mitogen-activated protein kinase. Journal of Physiology 520 399-406. (doi:10.1111/j.1469-7793.1999.00399.x)

Baumann B, Weber CK, Troppmair J, Whiteside S, Israel A, Rapp UR \& Wirth T 2000 Raf induces NF- $\mathrm{B}$ by membrane shuttle kinase MEKK1, a signaling pathway critical for transformation. PNAS 97 4615-4620. (doi:10.1073/pnas.080583397)

Blencowe H, Cousens S, Chou D, Oestergaard M, Say L, Moller AB, Kinney M, Lawn J, Born G \& G Born Too Soon Preterm Birth Action 2013 Born too soon: the global epidemiology of 15 million preterm births. Reproductive Health 10 (Suppl 1) S2. (doi:10.1186/1742-4755-10-S1-S2)

Bowen JM, Chamley L, Keelan JA \& Mitchell MD 2002 Cytokines of the placenta and extra-placental membranes: roles and regulation during human pregnancy and parturition. Placenta 23 257-273. (doi:10.1053/ plac.2001.0782)

Bruder JT \& Kovesdi I 1997 Adenovirus infection stimulates the Raf/MAPK signaling pathway and induces interleukin-8 expression. Journal of Virology 71 398-404.

Chen J, Fuji K, Zhang LX, Roberts T \& Fu H 2001 Raf-1 promotes cell survival by antagonizing apoptosis signal-regulating kinase 1 through a MEK-ERK independent mechanism. PNAS 98 7783-7788. (doi:10.1073/ pnas.141224398)

Christiaens I, Zaragoza DB, Guilbert L, Robertson SA, Mitchell BF \& Olson DM 2008 Inflammatory processes in preterm and term parturition. Journal of Reproductive Immunology 79 50-57. (doi:10.1016/j.jri.2008. 04.002)

Edelblum KL, Goettel JA, Koyama T, McElroy SJ, Yan F \& Polk DB 2008 a TNFR1 promotes tumor necrosis factor-mediated mouse colon epithelial cell survival through RAF activation of NF- $\mathrm{K}$ B. Journal of Biological Chemistry 283 29485-29494. (doi:10.1074/jbc.M801269200)

Edelblum KL, Washington MK, Koyama T, Robine S, Baccarini M \& Polk DB $2008 b$ Raf protects against colitis by promoting mouse colon epithelial cell survival through NF-к B. Gastroenterology 135 539-551. (doi:10. 1053/j.gastro.2008.04.025)

Ehrenreiter K, Piazzolla D, Velamoor V, Sobczak I, Small JV, Takeda J, Leung T \& Baccarini M 2005 Raf-1 regulates Rho signaling and cell migration. Journal of Cell Biology 168 955-964. (doi:10.1083/jcb.200409162)
Ehrenreiter K, Kern F, Velamoor V, Meissl K, Galabova-Kovacs G, Sibilia M \& Baccarini M 2009 Raf-1 addiction in Ras-induced skin carcinogenesis. Cancer Cell 16 149-160. (doi:10.1016/j.ccr.2009.06.008)

Elliott CL, Loudon JAZ, Brown N, Slater DM, Bennett PR \& Sullivan MHF 2001 IL-1 $\beta$ and IL-8 in human fetal membranes: changes with gestational age, labor, and culture conditions. American Journal of Reproductive Immunology 46 260-267. (doi:10.1034/ j.1600-0897.2001.d01-11.x)

Erkinheimo TL, Saukkonen K, Narko K, Jalkanen J, Ylikorkala O \& Ristimaki A 2000 Expression of cyclooxygenase-2 and prostanoid receptors by human myometrium. Journal of Clinical Endocrinology and Metabolism 85 3468-3475. (doi:10.1210/jcem.85.9.6809)

Geppert TD, Whitehurst CE, Thompson P \& Beutler B 1994 Lipopolysaccharide signals activation of tumor necrosis factor biosynthesis through the ras/raf-1/MEK/MAPK pathway. Molecular Medicine 1 93-103.

Ghoda L, Lin X \& Greene WC 1997 The 90-kDa ribosomal S6 kinase (pp90rsk) phosphorylates the $\mathrm{N}$-terminal regulatory domain of $\mathrm{I} \mathrm{B} \boldsymbol{\mathrm { B }} \alpha$ and stimulates its degradation in vitro. Journal of Biological Chemistry 272 21281-21288. (doi:10.1074/jbc.272.34.21281)

Karin M \& Delhase M 2000 The I $\kappa$ B kinase (IKK) and NF-к B: key elements of proinflammatory signalling. Seminars in Immunology 12 85-98. (doi:10.1006/smim.2000.0210)

Keelan JA, Blumenstein M, Helliwell RJ, Sato TA, Marvin KW \& Mitchell MD 2003 Cytokines, prostaglandins and parturition - a review. Placenta 24 S33-S46. (doi:10.1053/plac.2002.0948)

Khanjani S, Terzidou V, Johnson MR \& Bennett PR 2012 NFkB and AP-1 drive human myometrial IL8 expression. Mediators of Inflammation 2012 504952. (doi:10.1155/2012/504952)

Kyriakis JM \& Avruch J 1996 Sounding the alarm: protein kinase cascades activated by stress and inflammation. Journal of Biological Chemistry 271 24313-24316. (doi:10.1074/jbc.271.40.24313)

Lappas M 2015 KLF5 regulates infection- and inflammation-induced prolabour mediators in human myometrium. Reproduction 149 413-424. (doi:10.1530/REP-14-0597)

Lappas M \& Rice GE 2004 Phospholipase A2 isozymes in pregnancy and parturition. Prostaglandins, Leukotrienes, and Essential Fatty Acids $\mathbf{7 0}$ 87-100. (doi:10.1016/j.plefa.2003.04.001)

Lappas M \& Rice GE 2007 The role and regulation of the nuclear factor $\kappa$ B signalling pathway in human labour. Placenta 28 543-556. (doi:10. 1016/j.placenta.2006.05.011)

Lappas M, Permezel M, Georgiou HM \& Rice GE 2002 Nuclear factor $\kappa$ B regulation of proinflammatory cytokines in human gestational tissues in vitro. Biological Reproduction 67 668-673. (doi:10.1095/biolreprod67. 2.668)

Lappas M, Permezel M \& Rice GE 2003 N-acetyl-cysteine inhibits phospholipid metabolism, proinflammatory cytokine release, protease activity, and nuclear factor- $\kappa \mathrm{B}$ deoxyribonucleic acid-binding activity in human fetal membranes in vitro. Journal of Clinical Endocrinology and Metabolism 88 1723-1729. (doi:10.1210/jc.2002-021677)

Lappas M, Permezel M \& Rice GE 2007 Mitogen-activated protein kinase proteins regulate LPS-stimulated release of pro-inflammatory cytokines and prostaglandins from human gestational tissues. Placenta $\mathbf{2 8}$ 936-945. (doi:10.1016/j.placenta.2007.02.009)

Lappas M, Riley C, Lim R, Barker G, Rice GE, Menon R \& Permezel M 2011 MAPK and AP-1 proteins are increased in term pre-labour fetal membranes overlying the cervix: regulation of enzymes involved in the degradation of fetal membranes. Placenta 32 1016-1025. (doi:10.1016/ j.placenta.2011.09.011)

Lim R, Barker G \& Lappas M 2013 A novel role for FOXO3 in human labor: increased expression in laboring myometrium, and regulation of proinflammatory and prolabor mediators in pregnant human myometrial cells. Biological Reproduction 88 156. (doi:10.1095/biolreprod.113.108126)

Lim R, Barker G \& Lappas M 2014 TREM-1 expression is increased in human placentas from severe early-onset preeclamptic pregnancies where it may be involved in syncytialization. Reproductive Sciences $\mathbf{2 1}$ 562-572. (doi:10.1177/1933719113503406)

Lim R, Tran HT, Liong S, Barker G \& Lappas M 2016 The transcription factor interferon regulatory factor-1 (IRF1) plays a key role in the terminal effector pathways of human preterm labor. Biology of Reproduction 94 32. (doi:10.1095/biolreprod.115.134726)

Lindstrom TM \& Bennett PR 2005 The role of nuclear factor $\kappa$ B in human labour. Reproduction 130 569-581. (doi:10.1530/rep.1.00197) 
Liong S \& Lappas M 2015 The stress-responsive heme oxygenase (HO)-1 isoenzyme is increased in labouring myometrium where it regulates contraction-associated proteins. American Journal of Reproductive Immunology 74 62-76. (doi:10.1111/aji.12366)

Lu K, Liang CL, Liliang PC, Yang CH, Cho CL, Weng HC, Tsai YD, Wang KW \& Chen HJ 2010 Inhibition of extracellular signal-regulated kinases 1/2 provides neuroprotection in spinal cord ischemia/reperfusion injury in rats: relationship with the nuclear factor- $\kappa B$-regulated anti-apoptotic mechanisms. Journal of Neurochemistry 114 237-246. (doi:10.1111/j. 1471-4159.2010.06747.x)

Mebratu Y \& Tesfaigzi Y 2009 How ERK1/2 activation controls cell proliferation and cell death is subcellular localization the answer? Cell Cycle 8 1168-1175. (doi:10.4161/cc.8.8.8147)

Meloche S \& Pouyssegur J 2007 The ERK1/2 mitogen-activated protein kinase pathway as a master regulator of the G1- to S-phase transition. Oncogene 26 3227-3239. (doi:10.1038/sj.onc.1210414)

Nakano H, Shindo M, Sakon S, Nishinaka S, Mihara M, Yagita H \& Okumura K 1998 Differential regulation of $\mathrm{I} \mathrm{KB}$ kinase $\alpha$ and $\beta$ by two upstream kinases, NF- $\kappa B$-inducing kinase and mitogen-activated protein kinase/ERK kinase kinase-1. PNAS95 3537-3542. (doi:10.1073/pnas.95. 7.3537)

Osman I, Young A, Ledingham MA, Thomson AJ, Jordan F, Greer IA \& Norman JE 2003 Leukocyte density and pro-inflammatory cytokine expression in human fetal membranes, decidua, cervix and myometrium before and during labour at term. Molecular Human Reproduction 9 41-45. (doi:10.1093/molehr/gag001)

Paul J, Maiti K, Read M, Hure A, Smith J, Chan EC \& Smith R 2011 Phasic phosphorylation of caldesmon and ERK $1 / 2$ during contractions in human myometrium. PLOS ONE 6 e21542. (doi:10.1371/journal.pone. 0021542)

Rauk PN \& Chiao JP 2000 Interleukin-1 stimulates human uterine prostaglandin production through induction of cyclooxygenase-2 expression. American Journal of Reproductive Immunology 43 152-159. (doi:10.1111/j.8755-8920.2000.430304.x)

Roh CR, Oh WJ, Yoon BK \& Lee JH 2000 Up-regulation of matrix metalloproteinase- 9 in human myometrium during labour: a cytokinemediated process in uterine smooth muscle cells. Molecular Human Reproduction 6 96-102. (doi:10.1093/molehr/6.1.96)
Romero R \& Tartakovsky B 1992 The natural interleukin-1 receptor antagonist prevents interleukin-1-induced preterm delivery in mice. American Journal of Obstetrics and Gynaecology 167 1041-1045. (doi:10.1016/S0002-9378(12)80035-4)

Romero R, Mazor M \& Tartakovsky B 1991 Systemic administration of interleukin-1 induces preterm parturition in mice. American Journal of Obstetrics and Gynaecology 165 969-971. (doi:10.1016/00029378(91)90450-6)

Roskoski R Jr 2012 ERK1/2 MAP kinases: structure, function, and regulation. Pharmacology Research 66 105-143. (doi:10.1016/j.phrs. 2012.04.005)

Sadowsky DW, Adams KM, Gravett MG, Witkin SS \& Novy MJ 2006 Preterm labor is induced by intraamniotic infusions of interleukin-1beta and tumor necrosis factor-alpha but not by interleukin- 6 or interleukin-8 in a nonhuman primate model. American Journal of Obstetrics and Gynaecology 195 1578-1589. (doi:10.1016/j.ajog.2006.06.072)

Shynlova O, Lee YH, Srikhajon K \& Lye SJ 2013 Physiologic uterine inflammation and labor onset: integration of endocrine and mechanical signals. Reproductive Sciences 20 154-167. (doi:10.1177/1933719112446084)

Tattersall M, Engineer N, Khanjani S, Sooranna SR, Roberts VH, Grigsby PL, Liang Z, Myatt L \& Johnson MR 2008 Pro-labour myometrial gene expression: are preterm labour and term labour the same? Reproduction 135 569-579. (doi:10.1530/REP-07-0461)

Thomson AJ, Telfer JF, Young A, Campbell S, Stewart CJ, Cameron IT, Greer IA \& Norman JE 1999 Leukocytes infiltrate the myometrium during human parturition: further evidence that labour is an inflammatory process. Human Reproduction 14 229-236. (doi:10.1093/ humrep/14.1.229)

Tribe RM, Moriarty P, Dalrymple A, Hassoni AA \& Poston L 2003 Interleukin-1 $\beta$ induces calcium transients and enhances basal and store operated calcium entry in human myometrial smooth muscle. Biological Reproduction 68 1842-1849. (doi:10.1095/biolreprod.102.011403)

Received 21 December 2015

First decision 8 January 2016

Revised manuscript received 18 January 2016

Accepted 25 January 2016 